\title{
Assessment of Rational use of Antibiotics in Orthopedic Surgery Procedures
}

\author{
T. Veena Priyanka Anand*, S. Kavya Sree, S. Pavani, G. Manju Bhargavi, Shubham Babu Gupta \\ Pharm D, Malla Reddy Institute of Pharmaceutical Sciences, Dhulapally, Hyderabad, Telangana, INDIA.
}

\begin{abstract}
Introduction: Appropriate use of antimicrobial agents is important and is essential if the usefulness of antibiotic is to be preserved and the further spread of resistance is to be limited. Antibiotics are one of the pillars of modern medicine are important in prophylaxis and treatment of infectious diseases. Objective: To assess rational use of antibiotics for prophylaxis and treatment among patients in orthopedic department who undergone surgery. Methods: A prospective and observational study was conducted on 300 medical records of orthopedic patients who undergone surgery. Data was collected by using structured questionnaire from Sep 2019 to Dec 2019 and then analyzed using SPSS version 20.0 software. Results: Out of 300 patients who undergone surgery 179 patients were male and 121 patients were females. Based on age group classification $30-40$ years of age i.e. $50(38.46 \%)$ was mostly affected. The most common diagnosis was ORIF(43.07\%) followed by THR (20\%) of cases. The most frequently prescribed antibiotics for prophylaxis Cefuroxime $(67.40 \%)$, amikacin $(14.91 \%)$ and for treatment Cefuroxime (58.17\%), amikacin (18.90\%). The commonly used antibiotics combination for prophylaxis is Ceftriaxone +
\end{abstract}

Amikacin+ Cefuroxime $(20.68 \%)$ and treatment includes Ceftriaxone+ Cefuroxime + clavulanic acid $(34.04 \%)$. It was found that $50 \%$ of cases for prophylaxis was inappropriate where as $73.07 \%$ of treatment antibiotics failed to adhere guidelines. Conclusion: Generally, this study indicated that orthopedic patients underwent surgical procedures by majority of patients were ORIF and THR. Mostly prescribed antibiotics were cefuroxime, Amikacin. This study result indicated some level of inappropriateness in antibiotic prescription.

Key words: Antibiotics, Surgery, Resistance, Prophylaxis, Treatment.

Correspondence

T. Veena Priyanka Anand,

Pharm D, Malla Reddy Institute of Pharmaceutical Sciences, Dhulapally, Hyderabad, 500014, Telangana, INDIA.

Email: priyanka98.pa@gmail.com

DOI: $10.5530 /$ jyp.2020.12s.56

\section{INTRODUCTION}

Antibiotic agents are one of the mainstays of current clinical consideration and assumes significant job both in prophylaxis and treatment of irresistibleillnesses. The issues of their accessibility, choice and appropriate use are of basic significance to the worldwide network. Antibiotic abuses are be that as it may, an overall issue with the degree of the issue being more prominent in the creating nations through their buy (without solution) in nearby drug stores and medication stores and through unseemly endorsing propensities and an over-Zealous want to treat serious infections. ${ }^{1}$ Prophylactic antibiotic agents are broadly utilized in surgeries and record for generous antibiotic use in numerous emergency clinics. The motivation behind SAP is to diminish the commonness of postoperative injury contamination (about $5 \%$ of careful cases by and large) at or around the careful site. By forestalling careful site contaminations, prophylactic antimicrobial specialists can possibly diminish persistent horribleness and hospitalization costs for some surgeries that present critical danger of disease. Be that as it may, the advantages of prophylaxis are dubious; prophylaxis isn't defended for some surgeries (e.g., urologic tasks in patients with clean pee). Subsequently, the wrong or unpredictable utilization of prophylactic anti-infection agents can build the danger of medication poisonous quality, determination of safe life forms and costs. $^{2}$ Genuine horribleness and mortalities are related with postusable injury contaminations. They enormously affect patient's personal satisfaction and contribute considerably to the monetary expense of patient consideration. The utilization of preoperative anti-infection agents has become a basic segment of the standard of care in essentially all surgeries and has brought about a diminished danger of the postusable contamination when sound and fitting standards of prophylaxis are applied. ${ }^{3}$ In 1960s it was accounted for those pathogens are available during medical procedure paying little mind to how aseptic the medical procedure may show up. Besides, the relationship between's prophylactic antibiotics and post-employable would diseases were illustrated. Hence, antibiotic prophylaxis currently utilized in practically all surgeries, the preoperative organization of anti-infection agents since it can act when the injury is possibly debased that the utilization of antibiotics following 3-4 hrs of a bacterial entry point is unsatisfactory. ${ }^{4}$ Previous examinations have exhibited that antibiotic must be dynamic against major foreseen pathogens and more likely than not arrived at adequate focus in the tissue or body liquids in danger when of bacterial difficulties. In the event that prophylactic treatment is to be maximally powerful in lessening the disease pace of possibly sullied medical procedure. The requirement for proceeding with antibiotic prophylaxis of activity, not withstanding, has been unsure. ${ }^{5}$

Various investigations had demonstrated that there is high extent of unseemly anti-infection agents use for patients who conceded at careful ward and these examinations have likewise proposed explanations behind unseemliness as an exorbitant span of treatment, off base planning of organization, insufficient antibacterial range of the medications utilized and superfluous blend of two antibiotics. ${ }^{6-9}$ The expansion opposition destiny of numerous significant pathogens to as of now most accessible anti-toxin has been perceived as a significant and conceivably hazardous issue. This issue is advanced partially by nonsensical antibiotic endorsing is conduct and use. Restoratively in suitable, in viable and financially wasteful utilization of pharmaceuticals is normal social insurance frameworks issue all through the world particularly in the creating comities. ${ }^{10-16}$ This investigation planned for recognizing wrong 
utilization of anti-infection agents for prophylaxis and treatment at careful ward which fill in as a pattern information for wellbeing authority and arrangement creator and it helps in creating techniques or basic medication list rule for sound utilization of medications at the emergency clinic level just as for development of medical clinic administration.

\section{MATERIALS AND METHODS}

Study setting: The investigation was directed in Tertiary consideration Hospital in Orthopedic ward. The examination was directed from September 2019 to December 2019.

Study design: Prospective and Observational examination on appraisal of medication use was led utilizing patients' clinical card. Source populace: All clinical records of patients, who experienced significant medical procedure from September 2019 to December 2019.

\section{Eligibility criteria}

Inclusive criteria: The investigation incorporates the arbitrarily chosen perfect and tainted medical procedures Patients experiencing orthopedic medical procedure, patients all things considered and either sex.

Exclusive criteria: Patients with affirmed microbiological testing characteristic of contamination, diabetic patients, minor cuts and pregnancy cases were barred from study.

Sample size: The base measurably required example size was determined by utilizing the accompanying recipe.

$$
\mathrm{N}=\mathrm{Z} 2 \mathrm{P}(1-\mathrm{P})
$$

$\mathrm{D}^{2}$

Where:

$\mathrm{N}=$ Sample size required

$\mathrm{P}=$ Prevalence pace of antibiotics

$\mathrm{Z}=$ The standard typical Confidence at interim of $95 \%=1.96$

$\mathrm{D}=$ The edge of testing blunder endured

\section{Sampling techniques}

Stratified arbitrary examining strategy was directed to choose increasingly agent test. During study period, to figure test apportioned to every stratum proportionate portion was utilized. At that point a straight forward irregular testing was finished relying upon the kind of portion.

Where: in is test size of the it stratum

$\mathrm{Ni}$ is populace size of the ith stratum

\section{Study variables}

Independent variable: Age, Sex, Diagnosis, living arrangement, number of antibiotics utilized, term of clinic remain.

\section{Dependent variable}

Appropriateness of antibiotic use.

\section{Data collection procedure}

Significant data about every patient like segment factors, sort of determination, drug history (anti-infection agents utilized for prophylaxis and treatment including other prescription utilized), other co morbid conditions, spans of hospitalization remain and state of release were recorded utilizing all around organized information assortment group through checking on clinical records of patients. Other beneficial data was acquired from register. Propriety of anti-infection utilize was checked by utilizing the W.H.O Standard Guidelines for general medical clinics. ${ }^{17}$

\section{Data quality control}

To amplify precision of this investigation, information assortment design was approved with its target and grew enough to evaluate the goal of the examination. This information assortment group was pre-tried on $5 \%$ of patient's cards from a similar source populace before beginning genuine information assortment. Patient's cards which utilized for pre-testing isn't utilized in study. What's more, standard test for fulfillment and consistency of the information was made on consistent schedule. To check the consistency, information were entered in two diverse SPSS programs (twofold technique).

A review cross-sectional examination was led on 228 clinical records of patients who experienced significant medical procedure at Nekemte Referral Hospital during February 2017 to February 2018.Out of 228 patients who experienced significant medical procedure 177 patients were male and 51 patients were females. In light old enough gathering grouping $<20(21.1 \%)$ was generally influenced. The most widely recognized finding was appendectomy $(32.9 \%)$ followed generous prostate hyperplasia $(20.2 \%)$. The most every now and again endorsed anti-infection agents drugs was ceftriaxone (52.88\%), trailed by Metronidazole $(29.58 \%)$ for treatment and for prophylaxis ceftriaxone (71.96\%) followed metronidazole (17.56\%). The most utilized class of medication for prophylaxis was cephalosporin (72.45\%) also, Nitro imidazole (17.35\%); and for treatment cephalosporin (56.81\%) trailed by Nitro imidazole $(29.58 \%)$. this investigation result demonstrated some degree of impropriety which high light requirement for mediation. ${ }^{19}$

This examination was attempted to assess the example of anti-infection remedies in an optional social insurance setting in Kyrgyzstan. A review investigation was performed of anti-infection solutions in 251 inpatient records of patients admitted to the Sokuluk Territorial Hospital. A sum of 19 unique anti-infection agents were endorsed. Penicillin G (24.9\%), gentamicin (16.1\%), metronidazole (15.6\%) and cefazolin (14.5\%) were those most as often as possible prescribed.The most regular explanation given for impropriety was the unjustified (not showed) utilization of anti-infection agents in $143(48.6 \%)$ cases. ${ }^{20}$

In a study 262 patients were conceded with intestinal obstacle. The predominance of intestinal obstacle was $21.8 \%$ and $4.8 \%$ among patients

Table 1: Socio-demographic characteristics cross tabulation within appropriateness of antibiotic used for patients who undergone orthopedic surgery at surgical ward of Tertiary care Hospitals from September 2019 to December 2019.

\begin{tabular}{|c|c|c|c|c|}
\hline \multirow[t]{2}{*}{ S.No. } & \multirow{2}{*}{$\begin{array}{c}\text { Socio- } \\
\text { demographic } \\
\text { characteristics }\end{array}$} & \multirow[t]{2}{*}{$\begin{array}{l}\text { Frequency } \\
\qquad \mathrm{N}(\%)\end{array}$} & \multicolumn{2}{|c|}{$\begin{array}{c}\text { Inappropriateness of antibiotic } \\
\text { used }\end{array}$} \\
\hline & & & $\begin{array}{c}\text { For } \\
\text { Prophylaxis } \\
\text { N (\%) }\end{array}$ & $\begin{array}{c}\text { For Treatment } \\
\qquad N(\%)\end{array}$ \\
\hline \multirow[t]{9}{*}{1} & \multicolumn{4}{|c|}{ Age group (year) } \\
\hline & $0-10$ & $8(2.6)$ & $2(1.77)$ & $1(0.46)$ \\
\hline & $11-20$ & $13(4.44)$ & $1(0.88)$ & $7(3.25)$ \\
\hline & $21-30$ & $38(12.6)$ & $12(10.6)$ & $22(10.23)$ \\
\hline & $31-40$ & $72(24)$ & $30(26.54)$ & $56(26)$ \\
\hline & $41-50$ & $36(12)$ & $24(21.24)$ & 35 (16.27) \\
\hline & $51-60$ & $56(18.66)$ & $20(17.69)$ & $36(16.7)$ \\
\hline & $>60$ & $75(25)$ & $24(21.24)$ & $58(26.97)$ \\
\hline & Total & $300(100)$ & $113(100)$ & $215(100)$ \\
\hline \multirow[t]{3}{*}{2} & \multicolumn{4}{|c|}{ Sex } \\
\hline & Male & $180(59.67)$ & $74(65.48)$ & $135(62.79)$ \\
\hline & Female & $120(40)$ & $39(34.5)$ & $80(37.2)$ \\
\hline
\end{tabular}

$\mathrm{N}$ - is the number of patients 
Table 2: Types of diagnosis of orthopedic surgery at Tertiary care Hospitals from September 2019 to December 2019.

\begin{tabular}{ccc}
\hline Diagnosis & Frequency & Percentage (\%) \\
\hline ORIF & 117 & 39 \\
Total Hip Replacement & 30 & 10 \\
Wound Debridement & 32 & 10.7 \\
Arthroplasty & 40 & 13.3 \\
Implants & 19 & 6.3 \\
CRIF & 24 & 8 \\
TKR & 35 & 11.67 \\
Skin grafting & 03 & 1 \\
Total & 300 & 100 \\
\hline
\end{tabular}

Table 3: Total antibiotics used for surgical prophylaxis and treatment at for a patient who undergone orthopedic surgery September 2019 to December 2019.

\begin{tabular}{|c|c|c|}
\hline \multirow{2}{*}{ Drug name } & Prophylaxis & Treatment \\
\hline & No of patients $\mathrm{N}(\%)$ & No of patients $\mathrm{N}(\%)$ \\
\hline Cefuroxime & $247(70.57)$ & $242(52.95)$ \\
\hline Amikacin & $35(10)$ & $63(13.78)$ \\
\hline Metronidazole & $17(4.85)$ & $30(6.56)$ \\
\hline $\begin{array}{l}\text { Amoxicillin/potassium } \\
\text { clavulanate }\end{array}$ & $17(4.85)$ & $17(3.71)$ \\
\hline Ceftriaxone & $11(3.14)$ & $07(1.53)$ \\
\hline Cefoperazone / sulbactam & $15(4.28)$ & $17(3.71)$ \\
\hline $\begin{array}{l}\text { Cefuroxime/ clavulanic } \\
\text { acid }\end{array}$ & $02(0.57)$ & $56(12.25)$ \\
\hline Levofloxacin & $02(0.57)$ & $02(0.44)$ \\
\hline Linezolid & $02(0.57)$ & 05 (1.09) \\
\hline Cefotaxime & $02(0.57)$ & $14(3.06)$ \\
\hline cefixime & - & $4(0.87)$ \\
\hline Total & $350(100 \%)$ & $457(100 \%)$ \\
\hline
\end{tabular}

conceded for intense midsection medical procedure and all out careful confirmations, individually. In the wake of controlling for conceivable perplexing components, the significant indicators of the board result of intestinal deterrent were: term of ailment before careful intercession (balanced chances proportion $(\mathrm{AOR})=0.49,95 \% \mathrm{CI}: 0.25-0.97)$; intrausable discoveries [Viable little inside volvulus (SBV) ( $\mathrm{AOR}=0.08,95 \%$ CI: 0.01-0.95) and suitable ( $\mathrm{AOR}=0.17,95 \% \mathrm{CI}$ : 0.03-0.88)]; finishing of intra-usable strategies (entrail resection and anastomosis $(\mathrm{AOR}=3.05$, $95 \%$ CI: 1.04-8.94); and length of medical clinic remain $(\mathrm{AOR}=0.05,95$ \% CI: $0.01-0.16) .{ }^{21}$

\section{Data analysis and presentation}

Information section and examination was completed utilizing factual bundle for sociology (SPSS) adaptation 20.0. Enlightening measurements were utilized for factual examination. The outcome was broke down and introduced utilizing tables and charts. Information accessible was deciphered and examined with the aftereffects of comparative investigations.

\section{Ethical considerations}

A conventional letter was kept in touch with the Tertiary Hospitals so as to get consent to lead the investigation and Official authorization was
Table 5: Class of antibiotic used for prophylaxis and treatments for patient who undergone orthopedic surgery in Tertiary care Hospitals to September 2019 to December 2019.

\begin{tabular}{cccc}
\hline Class of antibiotic & $\begin{array}{c}\text { For prophylaxis } \\
\mathbf{N}(\%)\end{array}$ & $\begin{array}{c}\text { For treatment } \\
\mathbf{N}(\%)\end{array}$ & Total (\%) \\
\hline Cephalosporin's & $277(79.83)$ & $345(74.67)$ & $622(76.88)$ \\
Penicillin's & $40(11.5)$ & $44(9.52)$ & $84(10.38)$ \\
Nitro imidazole & $17(4.89)$ & $30(6.49)$ & $47(5.8)$ \\
$\begin{array}{c}\text { Oxazolidinone } \\
\text { antibiotic }\end{array}$ & $02(0.57)$ & $05(1.08)$ & $07(0.86)$ \\
Fluoroquinolones & $02(0.57)$ & $05(1.08)$ & $07(0.86)$ \\
Aminoglycosides & $8(2.3)$ & $32(6.93)$ & $40(4.94)$ \\
carbapenems & $1(0.288)$ & $1(0.216)$ & $2(0.25)$ \\
Total & $347(100)$ & $462(100)$ & $809(100)$ \\
\hline
\end{tabular}

Table 4: The appropriateness of antibiotic used for patients who undergone orthopedic surgery at Tertiary care Hospitals September 2019 to December 2019.

\begin{tabular}{|c|c|c|c|c|}
\hline $\begin{array}{l}\text { Reason for } \\
\text { use }\end{array}$ & Appropriateness & Frequency & \multicolumn{2}{|c|}{$\begin{array}{c}\text { Percentage } \\
\text { (\%) }\end{array}$} \\
\hline \multirow[t]{5}{*}{ Prophylaxis } & Appropriate & 187 & \multicolumn{2}{|c|}{62.33} \\
\hline & Inappropriate & Inappropriate choice & 53 & 17.67 \\
\hline & & $\begin{array}{l}\text { Unnecessary } \\
\text { combination }\end{array}$ & 40 & 13.33 \\
\hline & & Not mentioned & 20 & 6.67 \\
\hline & & Total & 113 & 37.67 \\
\hline \multirow[t]{6}{*}{ Treatment } & Appropriate & 85 & \multicolumn{2}{|c|}{28} \\
\hline & Inappropriate & Excessive duration & 96 & 32 \\
\hline & & Short duration & 03 & 1.0 \\
\hline & & Inappropriate choice & 54 & 18 \\
\hline & & $\begin{array}{l}\text { Unnecessary } \\
\text { combination }\end{array}$ & 62 & 20.67 \\
\hline & & Total & 215 & 71.67 \\
\hline
\end{tabular}

allowed from the medical clinic organization. To guarantee secrecy, name and different identifiers of patients and prescribers were not recorded on the information reflection groups.

\section{RESULTS}

\section{Socio-Demographic characteristics}

An aggregate of 300 patients' clinical records that experienced orthopedic medical procedure and took anti-infection agents' drugs were broke down. Most of the patients were between 30-40 year, 72 (24\%) and 41-50 years, 36 (12\%). Be that as it may, wrongness of antibiotics utilized for treatment was higher in age between 51-60 years or more 60 years. (Table 1)

\section{Therapeutic indication}

Out of 300 patients who underwent orthopedic medical procedure at, Tertiary Hospitals from September 2019 to December 2019. The most often analyzed malady for which antibiotic showed were ORIF 117 (39\%) trailed by Total Hip replacement 30 (10\%) (Table 2). 
Table 6: Combination of antibiotics used for prophylaxis and treatment for patients who undergone orthopedic surgery at Tertiary care Hospitals September 2019 to December 2019.

\begin{tabular}{|c|c|c|c|}
\hline Prophylaxis & Antibiotic combination & Frequency & Percentage \\
\hline & Ceftriazone+ Amikacin+ Cefuroxime & 06 & 11.3 \\
\hline & Metronidazole + Amikacin + Cefuroxime & 10 & 18.8 \\
\hline & Ceftazidine+ Amikacin & 05 & 9.4 \\
\hline & Flouroquinoloes + Amikacin & 05 & 9.4 \\
\hline & Levoflaxacin+Metronidazole+Amikacin & 03 & 5.6 \\
\hline & Flouroquinoloes + Amikacin + metronidazole & 02 & 3.7 \\
\hline & Ceftazidine+Amikacin+ cefixime & 01 & 1.8 \\
\hline & Ceftazidine + Amikacin+ceftrixone & 01 & 1.8 \\
\hline & Ceftrixone+ cefuroxime & 01 & 1.8 \\
\hline & Cefoperazone+sulbactum+amoxicillin+clavulanic acid & 12 & 22.6 \\
\hline & Cefuroxime+amikacin & 01 & 1.8 \\
\hline & amoxicillin+clavulanic acid + ceftriaxone & 01 & 1.8 \\
\hline & Cefuroxime+metronidazole & 03 & 5.6 \\
\hline & Cefotaxime+cefuroxime & 01 & 1.8 \\
\hline & Ceftriaxone+ amikacin & 01 & 1.8 \\
\hline & Total & 53 & 100 \\
\hline \multirow{29}{*}{ Treatment } & Ceftriaxone+ Cefuroxime + clavunalic acid & 18 & 13.6 \\
\hline & Ceftriaxone + Metronidazole + Amikacin & 11 & 8.3 \\
\hline & Cefoperazone +cefuroxime/clavinolic acid & 23 & 17.4 \\
\hline & Metronidazole+Amikacin & 05 & 3.7 \\
\hline & Levofloxacin + Metronidazole + Amikacin & 03 & 2.2 \\
\hline & Amikacin+Ceftriaxone & 03 & 2.2 \\
\hline & Levoflaxacin + Amikacin & 02 & 1.5 \\
\hline & Ceftazidine+Amikacin + Cefuroxime & 01 & 0.7 \\
\hline & Cefoperazone+sulbactum+amoxicillin+clavulanic acid & 04 & 3 \\
\hline & Cefoperazone+sulbactum+amoxicillin+clavulani acid + cefuroxime+clavulanic acid & 08 & 6 \\
\hline & Cefotaxim+metronidazole & 03 & 2.2 \\
\hline & Cefotaxim + metronidazole + cefuroxime & 01 & 0.7 \\
\hline & Cefuroxime+amikacin & 17 & 12.8 \\
\hline & Cefuroxime+cefotaxim & 03 & 2.2 \\
\hline & Cefuroxime+cefoperazone+sulbactum & 02 & 1.5 \\
\hline & Cefuroxime+cefoperazone+sulbactum+amikacin & 03 & 2.2 \\
\hline & Cefuroxime+amikacin+metronidazole & 11 & 8.3 \\
\hline & Ceftriaxone+cefuroxime & 02 & 1.5 \\
\hline & Cefotaxim+amikacin & 02 & 1.5 \\
\hline & Cefotaxim+amikacin+metronidazole+cefuroxime & 01 & 0.7 \\
\hline & Cefotaxim+amikacin+metronidazole & 01 & 0.7 \\
\hline & Ceftriaxone+amikacin+cefuroxime+metronidazole & 02 & 1.5 \\
\hline & Ceforperazone+sulbactum+linezolid+levofloxacin & 01 & 0.7 \\
\hline & Cefuroxime+cefixime & 01 & 0.7 \\
\hline & Meropenem+amikacin & 01 & 0.7 \\
\hline & Clindamycin+linezolid & 01 & 0.7 \\
\hline & Amoxicillin+clavulanicacid+ciprofloxacin & 01 & 0.7 \\
\hline & Amikacin+cefuroxime+levofloxacin & 01 & 0.7 \\
\hline & Total & 132 & 100 \\
\hline
\end{tabular}




\section{All antibiotic agents utilized for careful prophylaxis and treatment}

As appeared beneath in the Table 3, the most usually recommended antibiotic for patients who experienced orthopedic medical procedure for both Prophylaxis and Treatment Were Cefuroxime $70.57 \%$ and $52.95 \%$ individually, trailed by Amikacin 10\% and $13.78 \%$ (Table 3).

\section{Total antibiotics used for surgical prophylaxis and treatment}

300 patients were treated with various regiments of antibiotic agents' drugs. The quantities of patients who were treated with one antibiotic agents routine for prophylaxis were $76(58.91 \%)$ and for the treatment were $13(9.15 \%)$ and Two antibiotic agents routine was seen as $30(23.25 \%)$ and 95 (66.90\%), Three antibiotic routine $19(14.72 \%)$ and $20(14.08 \%)$ and Four antibiotic routine was seen as $4(3.10 \%)$ and $14(9.85 \%)$ separately.

\section{DISCUSSION}

This investigation distinguished that the predominance of ORIF was seen as (39.07\%) trailed by Total hip replacement which as saw in $10 \%$ of cases. Right now the endorsed antibiotic drugs Cefuroxime (70.57\%) for prophylaxis and $(52.95 \%)$ for treatment which was diverse with study done in Navy Hospital, Jakarta, Indonesia $87.8 \%$ however, gentamycin utilize was comparative in the same hospitals $3.66 \%$ and $3.7 \%$ respectively. ${ }^{13}$ In this examination (for treatment) the metronidazole recommended were $(29.58 \%)$, cloxacillin (3.66\%), ampicillin(5.5\%) and gentamycin (3.66\%)When we contrast and concentrate done in Manipal Teaching Hospital, Pokhara, Nepal ${ }^{12}$ the most ordinarily utilized individual antiinfection agents were arrangement of ampicillin and cloxacillin (54.64) trailed by metronidazole (31.95), ampicillin (18.34) and gentamicin (16.37), which was extraordinary yet there is no more distinction in the event of metronidazole.

In current examination the appropriate choice of antibiotic used in prophylaxis is 187 (62.33\%), and the inappropriate choice is based on choice of antibiotics 53 (17.67\%), unnecessary combination 40 (13.33\%), coming to treatment appropriateness of antibiotic $85(28 \%)$ and the inappropriateness is based on excessive duration 96 (32\%), short duration $3(1.0 \%)$, inappropriate choice 54 (18\%), unnecessary combination 62 (20.67\%). (Table 4)

In current examination the most endorsed antibiotic were Cefuroxime (70.57\%), Amikacin (10\%) and Metronidazole (4.85\%) for prophylaxis and $52.95 \%, 13.78 \%, 6.56 \%$ separately which was distinctive with study done in Orthopedic Surgical Unit of a Tertiary Care Teaching Hospital in Addis $\mathrm{Ababa}^{22}$ the most regularly recommended antbiotic specialist utilized for prophylaxis was ceftriaxone $(70 \%)$, cloxacillin $(9 \%)$ and Metronidazole (7\%) was utilized. Nonetheless, ceftriaxone was likewise recommended. The prophylactic antimicrobial regimens included both single just as mix regimens; single regimens in prophylaxis took the lion's offer. Right now most usually endorsed routine among the mix regimens was Ceftriazone +Amikacin + Cefuroxime (11.3\%), and metronidazole+ Amikacin + Cefuroxime (18.8\%), for treatment it is watched Ceftriaxone + Cefuroxime/Clavunalic corrosive (13.6\%) trailed by Ceftriazone + Amikacin + Metronidazole (8.3\%) (Table 6). This examination uncovered orthopedic medical procedure for prophylaxis were cephalosporin 277 (79.83\%), trailed by Penicillin's 40 (11.5\%) and Nitroimidazoles 17 (4.89\%). (Table 5) Correspondingly an examination done in Medicine careful inpatient wards of Basaweswara Medical College Hospital ${ }^{6}$ the most recommended antibiotics were third Generation Cephalosporin's 108 (40.7\%), trailed by Aminoglycoside 11 (4.2\%), Fluoroquinolones 11 (4.2\%) and Penicillin 9 (3.4\%).

The complete number of patients who were treated with mono therapy of anti-microbial medications for prophylaxis were 76 (58.91\%) and for the treatment 13 (9.15\%) and from hostile to microbial blends, two meds blend supported for prophylaxis were $30(23.25 \%)$ and for the treatment $95(66.90 \%)$ patients and three prescriptions mix for treatment were prescribed19(14.72\%) and for four medicine routine for prophylaxis $4(3.10 \%)$ and for treatment $14(9.85 \%)$ which was various with study done in drug careful in understanding wards of Tertiary consideration emergency clinic portion of them are on single enemy of contamination operators 73 (45.1\%), two enemy of disease specialists $75(46.3 \%)$ and three antimicrobials $14(8.6 \%)$ for prophylaxis. The reason behind the qualification could be an immediate consequence of the differentiation in study structure as the examination done in Tertiary consideration medical clinic was a planned report.

Limitation of this assessment was that the examination plan we used was Prospective and observational examination which is as often as possible at risk to tendencies (goofs that impact the impression of an assessment); for example, in the combination of information it is hard to assess how the patients took their drug and if there is any unwanted effect of the prescriptions. Being imminent assessment likewise made us not to contemplate significant factors including training level, adherence, calm prosperity expert correspondence and provider and prosperity structure related factors. Another obstacle was the little model size that we have used and that this assessment included only a solitary referral crisis facility of the nation.

\section{CONCLUSION}

We infer that, the prophylactic anti-microbial essentially diminish the rate of post- operative infection. Consistence with the standards of suitable antibiotic prophylaxis for medical procedure ought to be carefully investigated. To promote the rational use of antibiotics in surgical prophylaxis, suggestion for antimicrobial surgical prophylaxis is required. Also, adherence of the antimicrobial prophylaxis to these rules should be assessed routinely. There is a need to emphasize on the rational use of antibiotics in order to avoid antibiotic resistance and increase awareness among patients regarding the antibiotic usage.

\section{ACKNOWLEDGEMENT}

We consider this an opportunity to express our gratitude to all the dignitaries' who have been involved directly or indirectly in the successful completion of this dissertation.

We express our deep sense of gratitude and indebtedness to our respected guide Professor Dr. Shubham Babu Gupta, Assistant Professor, Malla Reddy Institute of Pharmaceutical Sciences, Secunderabad, whose comprehensive as well as effective supervision extended for beyond the duty of a guide.

Our sincere gratitude to the beloved principal Dr. B. Raj Kamal, Malla Reddy Institute of Pharmaceutical Sciences, Secunderabad, for providing every need from time to time to complete this work successfully.

\section{CONFLICT OF INTEREST}

The authors declare no conflict of interest.

\section{ABBREVIATIONS}

SAP: Surgical Antimicrobial Prophylaxis; SPSS: Statistical Package for Social Sciences; WHO: World Health Organization; ORIF: Open Reduction Internal Fixation; CRIF: Closed Reduction Internal Fixation; TKR: Total Knee Replacement.

\section{REFERENCES}

1. Imranuddin M, Asfin M, Sruthi V, Deshpande S, Reddy MVR, et al. Cost analysis and prescribing patterns of antibiotics in postoperative surgery patients. Indo 
Am J Pharm. 2015;5:2231-6876.

2. Alavi SM, Roozbeh F, Behmanesh F, Alavi L. Antibiotics use patterns for surgical prophylaxis site infection in different surgical wards of a teaching hospital in Ahvaz, Iran. Jundishapur J Microbiol. 2014;7:e12251.

3. Willems L, Simoen S, Laekeman G. Follow up of antibiotic prophylaxis impact on compliance with guidelines and financial out comes. J Hosp Infect. 2005;60(5):333-922.

4. Hoonk S, Hay J, Yook Y. (2009) The efficacy of postoperative prophylactic antibiotics in orthognathic: Surgery. Yoncei Med J. 2009;50(1):55-9.

5. Stone HH, Haney BB, Zaura D, Eard K, Geheber E, et al. Prophylactic and preventive antibiotic Therapy, timing, duration and economics. Ann Surg. 1979;189(6):691-8

6. Dinesh R, Moulya MV, Siddiq A, Bharathi DR. Evaluation of antibiotic usage as surgical prophylaxis in post-operative wards. Amer Jou of Pharm Tech Res. 2015:5:435-43.

7. Anguzu JR, Olila D. Drug sensitivity pattern of bacterial isolates from septic post-operative wound on a regional referral hospital Uganda. Afr Health Sci. 2007:8:148-54.

8. Martelli A, Mattioli FA. Retrospective study showing the misuse of prophylactic antibiotics in patients undergoing appendectomy and cholecystectomy. Current Thera Res. 2000;61(8):534-9

9. Sekimuto $M$, Immaka $Y$, Evans $E$, Ishizaki T, Fukui T. Practice variation in preoperative antibiotic use in Japan. Intern Jou for Quality in Health Care. 2004;16(5):367-73

10. Mohagheghi MA, Mosavi A, Khatemi M. Community based out patent practice of antibiotics use in Tehran. Pharm Epid Drug Saf. 2005;14(2):135-8.

11. Yang SF, Nadimi S, Eggerstedt M, Thorpe E, Pittman A. Antibiotic prophylaxis and postoperative wound infection rates in salvage surgery for head and neck cancer. Head Neck Cancer Res. 2016;1:1-5.

12. Kumar NS, Varaprasad CP, Thyag A, Sudarsanan S, Reddy YH. Prescribing pattern of antibiotics in surgical department in a tertiary care teaching hospital. World Jour of Pharma Res. 2016;5:1138-47.

13. Radji M, Aini F, Fauziyah S. Evaluation of antibiotic prophylaxis administration at the orthopedic surgery clinic of a tertiary hospital in Jakarta. Indonesia Asian Pac J Trop Dis. 2014;4(3):190-3.

14. Rajeshwari NH. Drug utilization study in postoperative patients in obstetrics and gynecology ward of tertiary care hospital. Int J Basic Clin Pharmacol. 2016;5:329-34.

15. Achong MR, Houser BA, Krusky JL. Rational and irrational use of antibiotics in a Canadian teaching hospital. Can med Assoc J. 1977;116(3):256-9.

16. Chaudhary K, Panka J, Atul J, Arvind MK, Gaurav, et al. Usage of antimicrobials in post-operative patients in a tertiary care teaching rural hospital in India. 2015;2:328-37.

17. Food, Medicine and Healthcare Administration and Control Authority of Ethiopia Standard Treatment Guidelines for General Hospital (3rd eds.) Ethiopia. 2014;1320.

18. Testa M, Stillo M, Giacomelli S, Scofonne S, Zotti CM. Appropriate use of antimicrobial prophylaxis: Un observation study in 21 surgical wards of Public hospital. BMC Surgery. 2015;15(1):63

19. Roy BC, Hanifa A, Alam S, Naher S, Sarkar P. Etiological spectrum of obstructive jaundice in tertiary care. Global Jou of Med Res. 2015;4:1-5.

20. Baktygul K, Marat B, Ashirali Z, Rashid H, Sakamoto J. An assessment of antibiotics prescribed at the secondary health-care level in the Kyrgyz republic. Nagoya Journal of Medical Science. 2011;73(3-4):157-68.

21. Soressa U, Mamo A, Hiko D, Prevalence FN. Prevalence, causes and management outcome of intestinal obstruction in Adama Hospital, Ethiopia. BMC Surgery. 2016;16(1):38

22. Argaw NA, Shumbash KZ, Asfaw AA, Hawaze S (2017) Assessment of surgical antimicrobial prophylaxis in orthopedic and traumatology surgical unit of tertiary care teaching hospital in Addis Ababa. BMC Res Notes 10: 2-8.

Article History: Submission Date : 10-03-2020; Revised Date : 13-05-2020; Acceptance Date : 31-05-2020.

Cite this article: Anand TVP, Sree SK, Pavani S, Bhargavi GM, Gupta SB. Assessment of Rational use of Antibiotics in Orthopedic Surgery Procedures. JYoung Pharm. 2020;12(2)Suppl:s102-s7. 